OPEN ACCESS

Edited by:

Zheng Ruan,

Nanchang University, China

Reviewed by:

Junqiu Luo,

Sichuan Agricultural University, China

Xiao Xu,

Wuhan Polytechnic University, China

${ }^{*}$ Correspondence: Bingcheng Gan ganbingcheng@caas.cn Weihong Peng whpeng768@163.com

Specialty section: This article was submitted to

Food Microbiology,

a section of the journal

Frontiers in Microbiology

Received: 15 July 2021

Accepted: 02 August 2021

Published: 06 September 2021

Citation:

Xu Y, Xie L, Tang J, He X

Zhang Z, Chen Y, Zhou J, Gan B and

Peng W (2021) Morchella importuna Flavones Improve Intestinal Integrity in Dextran Sulfate Sodium-Challenged Mice. Front. Microbiol. 12:742033. do: $10.3389 /$ fmicb.2021.742033

\section{Morchella importuna Flavones Improve Intestinal Integrity in Dextran Sulfate Sodium-Challenged Mice}

Yingyin $\mathrm{Xu}^{1}$, Liyuan Xie ${ }^{1}$, Jie Tang ${ }^{1}$, Xiaolan $\mathrm{He}^{1}$, Zhiyuan Zhang ${ }^{1}$, Ying Chen ${ }^{1}$, Jie Zhou ${ }^{1}$, Bingcheng Gan ${ }^{2 *}$ and Weihong Peng ${ }^{1 *}$

' National-Local Joint Engineering Laboratory of Breeding and Cultivation of Edible and Medicinal Fungi, Institute of Agricultural Resources and Environment, Sichuan Academy of Agricultural Sciences, Chengdu, China, ${ }^{2}$ Institute of Urban Agriculture, Chinese Academy of Agricultural Sciences, Chengdu, China

Morchella importuna, as an edible fungus, has various health benefits. However, the effects of $M$. importuna on intestinal health are rarely investigated. Hence, this study aims to ascertain the influences of flavones from the fruiting bodies of $M$. importuna (hereinafter abbreviated as MIF) on dextran sulfate sodium (DSS)-induced damage to intestinal epithelial barrier in C57BL/6J mice. In this (14-day) study, 144 C57BL/6J mice were divided into four groups: (1) Control; (2) DSS treatment; (3) DSS treatment + $100 \mathrm{mg} / \mathrm{kg}$ MIF (LMIF); (4) DSS treatment + 200 mg/kg MIF (HMIF). On days 814 , mice in the challenged groups were challenged with 3.5\% DSS, while the control group received an equal volume of normal saline. Then, serum and intestinal samples were obtained from all mice. The results showed that MIF ingestion enhanced intestinal integrity in DSS-challenged mice, as evinced by the elevated $(p<0.05)$ abundances of occludin, claudin-1, and zonula occludens-1 proteins. Meanwhile, MIF ingestion reduced $(\rho<0.05)$ the colonic interleukin-1 $\beta$ (IL-1 $\beta)$, tumor necrosis factor- $\alpha$ (TNF$\alpha)$, and interferon- $\gamma(\mathrm{IFN}-\gamma)$ concentrations and increased the superoxide dismutase and catalase activities and Shannon and Simpson indices in DSS-challenged mice. Moreover, MIF ingestion reduced $(p<0.05)$ the abundance of phospho-nuclear factor (NF)-кB and increased the abundance of phospho-Nrf2 in DSS-challenged mice. Taken together, MIF protects against intestinal barrier injury in C57BL/6J mice via a mechanism that involves inhibiting NF-kB activation and promoting Nrf2 activation, as well as regulating intestinal microbiota.

Keywords: Morchella importuna, intestinal barrier function, intestinal microbiota, inflammatory responses, C57BL/6 mice

\section{INTRODUCTION}

The intestinal epithelial barrier is a single layer of cells lining the gut that comprises the apical cell membrane and intercellular tight junctions of intestinal epithelial cells (Ulluwishewa et al., 2011; Peterson and Artis, 2014). It acts as a selective barrier that allows the absorption of nutrient substances while inhibiting the translocation of luminal pathogens (Halpern and Denning, 2015; 
Wang et al., 2015). Hence, treatments aimed at decreasing intestinal permeability contribute to improved health. Nowadays, dietary bioactive substances have been found to improve intestinal barrier function by strengthening the intestinal barrier, attenuating the inflammatory responses and modulating microbiota composition (Yang et al., 2012; Tian et al., 2019; Wan et al., 2020).

The Morchella mushroom, a type of edible ascomycetous mushroom, has a unique flavor, as well as a high nutritional value (Tietel and Masaphy, 2018). Interestingly, some bioactive compounds have been found in the Morchella mushroom fruiting body, such as polysaccharides, ergosterol derivatives, microthecin, and so on (Wang et al., 2019). Modern medical research demonstrated that the Morchella mushrooms confer antimicrobial, antioxidant, anti-inflammatory, and antitumor activities (Kim et al., 2011; Huang et al., 2012; Heleno et al., 2013). Therefore, the mature fruiting body of Morchella mushrooms have been used as a traditional herbal medicine in Asian countries, such as China, India, and Japan (Mau et al., 2004; Xiong et al., 2017). However, to the best of our knowledge, the ameliorative effects of Morchella mushrooms on intestinal barrier function have not been investigated and warrant exploration.

In the present work, the flavones from the fruiting bodies of $M$. importuna (MIF) were prepared. Then, the protective effects and possible mechanisms of MIF against the intestinal barrier injury in vivo were investigated using a sodium glucose sulfate [dextran sulfate sodium (DSS)]challenged mouse model.

\section{MATERIALS AND METHODS}

\section{Preparation of the Fruiting Bodies of Morchella importuna}

In this study, the MIF were collected from the experimental field of Sichuan Academy of Agricultural Sciences (Chengdu, China). The MIF were dried at $37^{\circ} \mathrm{C}$, and then $200 \mathrm{~g}$ of MIF were immersed in proportions of $1: 20(\mathrm{w} / \mathrm{v})$ in ethanol at $60^{\circ} \mathrm{C}$ for $6 \mathrm{~h}$. After centrifugation at $6,000 \times \mathrm{g}$ for $15 \mathrm{~min}$, the sediment was discarded. Thereafter, the resulting MIF was dried at $60^{\circ} \mathrm{C}$ and stored at $-20^{\circ} \mathrm{C}$ before use.

\section{Preliminary Characterization of the Fruiting Bodies of Morchella importuna}

The molecular weight distribution of MIF was determined by high-performance gel permeation chromatography (HP-GPC). The operating procedures were Waters 515, high-performance liquid chromatography equipped with laser detector (LS), and differential refractive index (DRI); Shodex OHpak series SB806 gel chromatographic column $(300 \mathrm{~mm} \times 7.8 \mathrm{~mm})$; column temperature $40^{\circ} \mathrm{C} \pm 0.1^{\circ} \mathrm{C}$. The mobile phase was $0.05 \mathrm{M}$ $\mathrm{NaH}_{2} \mathrm{PO}_{4}-\mathrm{NaH}_{2} \mathrm{PO}_{4}$ buffer ( $\mathrm{pH}$ 6.7, with $0.02 \% \mathrm{NaN}_{3}$ ). The flow rate was $0.5 \mathrm{ml} / \mathrm{min}$. The loading amount was $500 \mu \mathrm{l}$. Then, 0.05 $\mathrm{M} \mathrm{NaH}_{2} \mathrm{PO}_{4}-\mathrm{NaH}_{2} \mathrm{PO}_{4}$ buffer ( $\mathrm{pH}$ 6.7, with $0.02 \% \mathrm{NaN}_{3}$ ) is used to dissolve polysaccharide standards with the molecular weights of $738,5,800,1.22 \times 10^{4}, 2.37 \times 10^{4}, 4.8 \times 10^{4}, 1.0 \times 10^{5}$, $1.86 \times 10^{5}, 3.8 \times 10^{5}$, and $8.53 \times 10^{5} \mathrm{~g} / \mathrm{mol}$, respectively. After being filtered with $0.45-\mu \mathrm{m}$ membrane, the determination was performed according to the above chromatographic conditions. According to the molecular weight and retention time of standards, the standard curve was drawn, and then the molecular weight was calculated according to the retention time.

\section{Animals, Management, and Diet}

A total of $144 \mathrm{C} 57 \mathrm{BL} / 6 \mathrm{~J}$ mice (initial mass $18.02 \pm 0.36 \mathrm{~g}$ ), obtained from Dashuo Experimental Animal Co., Ltd. (Chengdu, China), were divided into four treatments with six pens per treatment (six mice per pen): (1) Control (fed a normal diet); (2) DSS treatment (fed a normal diet); (3) DSS treatment + $100 \mathrm{mg} / \mathrm{kg}$ MIF (LMIF; fed a normal diet + $100 \mathrm{mg} / \mathrm{kg}$ MIF); (4) DSS treatment $+200 \mathrm{mg} / \mathrm{kg}$ MIF (HMIF; fed a normal diet $+200 \mathrm{mg} / \mathrm{kg}$ MIF). On days 8-14, mice in the challenged groups were orally administered 3.5\% DSS in drinking water, while other mice were administered normal saline (Bassaganya-Riera and Hontecillas, 2006). Moreover, all mice were individually caged under a controlled environment room.

\section{Slaughter and Sample Collection}

At the end of the experiment, after 12-h starvation and ether anesthesia, blood samples from six mice with the average body weight in each group were collected, centrifuged at $1,500 \times \mathrm{g}(15 \mathrm{~min})$ to obtain serum, and then stored at $-20^{\circ} \mathrm{C}$. Subsequently, the same mice were sacrificed, about $2-\mathrm{cm}$ segments of the colon were isolated, gently flushed with normal saline, and then fixed in paraformaldehyde solution (4\%) for morphological analysis. Finally, about $5-\mathrm{cm}$ colonic tissues were collected and stored at $-80^{\circ} \mathrm{C}$ until analyses.

\section{Serum Biochemical Analysis}

The serum diamine oxidase (DAO) activity and D-lactate concentration were assessed using commercial kits purchased from Jiancheng Bioengineering Institute (Nanjing, China). All measurements were performed according to the manufacturer's instructions.

\section{Intestinal Morphology Analysis}

After a 48-h fixation, the colonic segments were dehydrated using a graded series of alcohol and cleaned with xylene, embedded in paraffin, cut into cross sections of 5- $\mu \mathrm{m}$ thickness, and then stained with H\&E (Fang et al., 2017). Then, the villus height and crypt depth were measured, and the ratio of villus height to crypt depth (VCR) was calculated from the value obtained above.

\section{Intestinal Cytokine Concentration Determinations}

The colonic mucosa was homogenized with normal saline (1:9), and the homogenate was centrifuged at $1,500 \times \mathrm{g}(15 \mathrm{~min})$ to attain supernatant. Then, the concentrations of interleukin$1 \beta$ (IL-1 $\beta)$, IL-6, IL-10, tumor necrosis factor- $\alpha$ (TNF- $\alpha$ ), and interferon- $\gamma(\mathrm{IFN}-\gamma)$ in the colonic mucosal supernatant were 
assayed by ELISA kits (Zhuo Cai Biotechnology Co., Ltd., Shanghai, China).

\section{Intestinal Antioxidant Capacity Measurements}

Superoxide dismutase (SOD) activity, catalase (CAT) activity, malondialdehyde (MDA) content, and total antioxidant capacity (T-AOC) in the colonic homogenates were measured. Measurements were performed by the spectrophotometric method using commercially available kits (Nanjing Jiancheng Bioengineering Institute).

\section{Intestinal Microbiota Analysis}

Total gDNA from digesta samples was extracted using a Stool DNA Isolation Kit (Tiangen Biotech Co., Ltd., Beijing, China), following the manufacturer's directions. The genes of bacterial 16S rRNA in the region of V4 were amplified by using PCR with primers (515F/806R). The PCR products were subjected to electrophoresis on 2\% agarose gel, and the mixed PCR products were purified with AxyPrep DNA Gel Extraction Kit (Axygen Biosciences, Union City, CA, United States) for sequencing on an Illumina MiSeq system. All 16S rRNA gene sequencing data were saved in the National Center for Biotechnology Information and can be accessed in the Short Read Archive under the accession number PRJNA679459. ${ }^{1}$

Quality filtering on the raw reads was performed under specific filtering conditions to obtain the high-quality clean reads according to the Cutadapt quality-controlled process (Martin, 2011). The reads were compared with the reference database using UCHIME algorithm (Edgar et al., 2011), to detect chimera sequences, and then removed to get the clean reads (Haas et al., 2011). Clustered into operational taxonomic units (OTUs) utilizing Uparse v7.0.1001 at 97\% sequence similarity (Edgar, 2013). Species annotation was carried out on the OTU representative sequences. For colonic bacteria, $\alpha$-diversity index was assessed using QIIME 1.7.0. Principal coordinate analysis ( $\mathrm{PCoA}$ ) tools in $\mathrm{R}$ language were used for PCoA.

\section{Western Blot Assay}

Protein samples were extracted from colonic tissues using lysis buffer (Beyotime Institute of Biotechnology, Shanghai, China). The lysates were centrifuged at $12,000 \times \mathrm{g}$ for $10 \mathrm{~min}$ at $4^{\circ} \mathrm{C}$, and the supernatant was collected. A bicinchoninic acid (BCA) protein assay kit (Beyotime Institute of Biotechnology) was used to determine the protein concentration in the supernatant. Thereafter, $30 \mu \mathrm{g}$ of protein extractions were separated by $10 \%$ sodium dodecyl sulfate (SDS)-polyacrylamide gel electrophoresis (PAGE) and then transferred to a polyvinyldifluoride (PVDF) membrane (Merck Millipore Ltd., Tullagreen, Ireland) using wet Trans-Blot System (Bio-Rad Laboratories, Inc., Hercules, CA, United States). After blocking with Tris-buffered saline Tween 20 (TBS/T) containing 5\% bovine serum albumin (BSA) at room temperature for $1 \mathrm{~h}$, the membranes were incubated

${ }^{1}$ http://www.ncbi.nlm.nih.gov/bioproject/679459 with primary antibodies at $4^{\circ} \mathrm{C}$ overnight against phospho-Nrf2 (Sigma-Aldrich, St. Louis, MO, United States), Keap1 (SigmaAldrich), heme oxygenase-1 (HO-1; Sigma-Aldrich), NAD (P)H dehydrogenase (quinone 1) (NQO-1; Sigma-Aldrich), occludin (Sigma-Aldrich), claudin-1 (Proteintech Group, Inc., Wuhan, China), zonula occludens-1 (ZO-1; Sigma-Aldrich), ZO-2 (Sigma-Aldrich), Toll-like receptor 4 (TLR4; Proteintech Group, Inc.), MyD88 (Proteintech Group, Inc.), IL-1 receptor-associated kinase 1 (IRAK1; Proteintech Group, Inc.), TNF receptorassociated factor 6 (TRAF6; Proteintech Group, Inc.), phosphoNF-кB (Proteintech Group, Inc.), or $\beta$-actin (Proteintech Group, Inc.). The polyvinylidene fluoride (PVDF) membranes were washed thrice with TBS/T, then incubated with second antibodies at room temperature for $2 \mathrm{~h}$, and washed thrice with TBS/T again. BeyoECL Moon (Beyotime Institute of Biotechnology) was used to visualize signals. The Image Lab software (Bio-Rad Laboratories, Inc.) was utilized to quantify protein abundance.

\section{Statistical Analysis}

Individual rat was used as the experimental unit, and all data were analyzed by SPSS 20.0 (SPSS, Inc., Chicago, IL, United States). Statistical differences between groups were determined by Student's $t$-test, while among groups, differences were determined by Tukey's multiple-range test. Results were presented as means \pm standard deviations. Differences were taken to indicate significance when $p<0.05$.

\section{RESULTS}

\section{Molecular Weight and Its Distribution of Morchella importuna Flavones}

From the results of HP-GPC detection, the mass average molar mass $(\mathrm{Mw})$ of MIF was $6.666 \times 10^{5} \mathrm{~g} / \mathrm{mol}$, the number average Molecular Weight (Mn) was $6.118 \times 10^{5} \mathrm{~g} / \mathrm{mol}$, and the D value (Mw/Mn) was 1.09. The dispersity ratio was close to 1 , and the molecular weight distribution was narrow, indicating that the MIF was relatively pure (Table $\mathbf{1}$ ).

TABLE 1 | Molecular weight and its distribution of Morchella importuna flavones.

\begin{tabular}{lc}
\hline Item & MIF \\
\hline $\mathrm{Mw}, \mathrm{g} / \mathrm{moL}$ & $6.666 \times 10^{5}$ \\
$\mathrm{Mn}, \mathrm{g} / \mathrm{moL}$ & $6.118 \times 10^{5}$ \\
$\mathrm{Mw} / \mathrm{Mn}$ & 1.09 \\
Molecular weight distribution, \% & \\
$500000.0-522000.0 \mathrm{~g} / \mathrm{moL}$ & 5.30 \\
$522000.0-558000.0 \mathrm{~g} / \mathrm{moL}$ & 44.80 \\
$558000.0-805000.0 \mathrm{~g} / \mathrm{moL}$ & 37.20 \\
$805000.0-1170000.0 \mathrm{~g} / \mathrm{moL}$ & 7.20 \\
$1170000.0-2012949.0 \mathrm{~g} / \mathrm{moL}$ & 5.60 \\
\hline
\end{tabular}

MIF, fruiting bodies of M. importuna. 
TABLE 2 | Effects of Morchella importuna flavones on the serum DAO activity and D-lactate concentration in DSS-challenged mice.

\begin{tabular}{lcccc}
\hline Item & \multicolumn{4}{c}{ Treatment $^{\dagger}$} \\
\cline { 2 - 5 } & CON & DSS & DSS + LMIF & DSS + HMIF \\
\hline $\mathrm{DAO}, \mathrm{U} / \mathrm{L}$ & $10.15 \pm 3.33$ & $15.86 \pm 4.92^{\star}$ & $11.15 \pm 4.87$ & $11.12 \pm 2.98^{\star}$ \\
$\begin{array}{l}\mathrm{D} \text {-Lactate } \\
\mathrm{pg} / \mathrm{ml}\end{array}$ & $14.91 \pm 3.71$ & $24.49 \pm 5.28^{\star *}$ & $16.29 \pm 3.84$ & $11.72 \pm 2.47^{\star *}$ \\
& & & & \\
\hline
\end{tabular}

${ }^{*} p<0.05$ or ${ }^{* *} p<0.01$.

${ }^{\dagger}$ CON, control; DSS, dextran sulfate sodium (DSS) treatment; DSS + LMIF, DSS treatment $+100 \mathrm{mg} / \mathrm{kg}$ fruiting bodies of M. importuna (MIF); DSS + HMIF, DSS treatment $+200 \mathrm{mg} / \mathrm{kg}$ MIF. DAO, diamine oxidase.

\section{Serum Indices}

DSS challenge enhanced $(p<0.05)$ the DAO activity and increased the concentration of D-lactate in C57BL/6J mice (Table 2). Dietary $200 \mathrm{mg} / \mathrm{kg}$ MIF inclusion reduced $(p<0.05)$ the serum D-lactate concentration in DSS-challenged mice.

\section{Intestinal Morphology}

Relative to the control mice, DSS challenge was found to reduce $(p<0.05)$ the colonic villus height without affecting crypt depth and VCR (Figure 1). Between the DSS-challenged mice, 100 and $200 \mathrm{mg} / \mathrm{kg}$ MIF supplementation increased $(p<0.05)$ the colonic villus height, and $200 \mathrm{mg} / \mathrm{kg}$ MIF supplementation additionally increased colonic VCR.

\section{Intestinal Antioxidant Capacity}

According to Table 3, it is found that DSS challenge decreased $(p<0.05)$ the SOD, CAT, and T-AOC activities and increased the MDA content in the colon of C57BL/6 mice. Supplementation with 100 and $200 \mathrm{mg} / \mathrm{kg}$ MIF increased $(p<0.05)$ the colonic SOD and CAT activities in DSS-challenged mice.

\section{Intestinal Cytokine Concentration}

Dietary $200 \mathrm{mg} / \mathrm{kg}$ MIF ingestion reduced $(p<0.05)$ the contents of the IL- $1 \beta$, TNF- $\alpha$, and IFN- $\gamma$ and increased $(p<0.05)$ the IL10 content in colonic mucosa of DSS-challenged mice (Table 4). Moreover, $100 \mathrm{mg} / \mathrm{kg}$ MIF supplementation increased $(p<0.05)$ the colonic mucosal IL-10 concentration in DSS-challenged mice.

\section{Tight Junction Protein Abundances}

Figure 2 shows the effects of MIF on tight junction protein (occludin, claudin-1, ZO-1, and ZO-2) abundances in DSSchallenged mice. DSS challenge decreased $(p<0.05)$ the abundances of occludin, claudin-1, and ZO-1 proteins. Dietary supplementation with 100 and $200 \mathrm{mg} / \mathrm{kg}$ MIF elevated $(p<0.05)$ the abundance of claudin- 1 protein, and $200 \mathrm{mg} / \mathrm{kg}$ MIF also increased $(p<0.05)$ the abundances of occludin and ZO-1 proteins in DSS-challenged mice.

\section{Nrf2 Pathway-Related Protein Abundances}

The differences in colonic Nrf2 pathway-related protein abundances among the four groups are shown in Figure 3. The colonic protein abundances of $\mathrm{p}-\mathrm{Nrf2}$ and $\mathrm{HO}-1$ were lower in the DSS group $(p<0.05)$ than that in the control group. However, supplementation with 100 and $200 \mathrm{mg} / \mathrm{kg}$ MIF increased $(p<0.05)$ the colonic protein abundances of p-Nrf2 and HO-1 in DSS-challenged mice. Neither DSS nor MIF affected $(p>0.05)$ the Keap1 and NQO-1 protein abundances in C57BL/6J mice.

\section{NF-кB Pathway-Related Protein Abundances}

Figure 4 shows that the DSS challenge elevated $(p<0.05)$ the TLR4, MyD88, IRAK1, TRAF6, and p-NF- KB protein abundances, whereas supplementation with $200 \mathrm{mg} / \mathrm{kg}$ MIF reduced $(p<0.05)$ the TLR4, MyD88, IRAK1, TRAF6, and p-NF$\kappa \mathrm{B}$ p65 protein abundances in DSS-challenged mice. Moreover, $100 \mathrm{mg} / \mathrm{kg}$ MIF downregulated $(p<0.05)$ the TLR4 protein abundance in DSS-challenged mice.

\section{Intestinal Microbial Diversity}

According to Table 5, it is found that DSS treatment decreased $(p<0.05)$ the Shannon index and Simpson index of bacteria in C57BL/6J mice. Supplementation with $200 \mathrm{mg} / \mathrm{kg}$ MIF increased $(p<0.05)$ the Shannon index and Simpson index of bacteria in DSS-challenged mice. Neither DSS nor MIF affected $(p>0.05)$ the Chao1 index or abundance-based coverage estimators (ACE) index of bacteria in C57BL/6J mice.

As shown in Figure 5, the PCoA revealed that microbial community was significantly altered after DSS challenge or MIF supplementation, with an evident separation $(p<0.05)$ among the three groups.

\section{Intestinal Microbiota Composition}

The bacterial composition was assessed at different taxonomic levels (Figure 6 and Supplementary Table 1). At the phylum level, the dominant bacterial groups were Bacteroidetes, Firmicutes, and Proteobacteria; these were followed by the bacteria from phyla Verrucomicrobia, Fusobacteria, Actinobacteria, Deferribacteres, Tenericutes, and Melainabacteria. DSS challenge decreased $(p<0.05)$ the abundances of Bacteroidetes and Verrucomicrobia, increased $(p<0.05)$ the abundances of Firmicutes, Proteobacteria, Deferribacteres, and Melainabacteria. However, $200 \mathrm{mg} / \mathrm{kg}$ MIF supplementation increased $(p<0.05)$ the abundances of Proteobacteria, Deferribacteres, and Melainabacteria.

\section{DISCUSSION}

Villus height, crypt depth, and VCR serve as criteria that reflect gross intestinal morphology (Liu et al., 2008; Qin et al., 2018). At present, the DSS challenge decreased colonic villus height, which suggests that DSS caused acute damage to intestinal mucosa. MIF supplementation increased colonic villus height and VCR, which implies that MIF improved intestinal structure. The maintenance of intestinal integrity primarily depends on the tight junctions between the enterocytes. Tight junctions are composed of several tight junction proteins, such as occludin and claudins, as well as cytoplasmic ZOs (Anderson et al., 1993). 
A

CON

DSS

DSS+LMIF DSS+HMIF
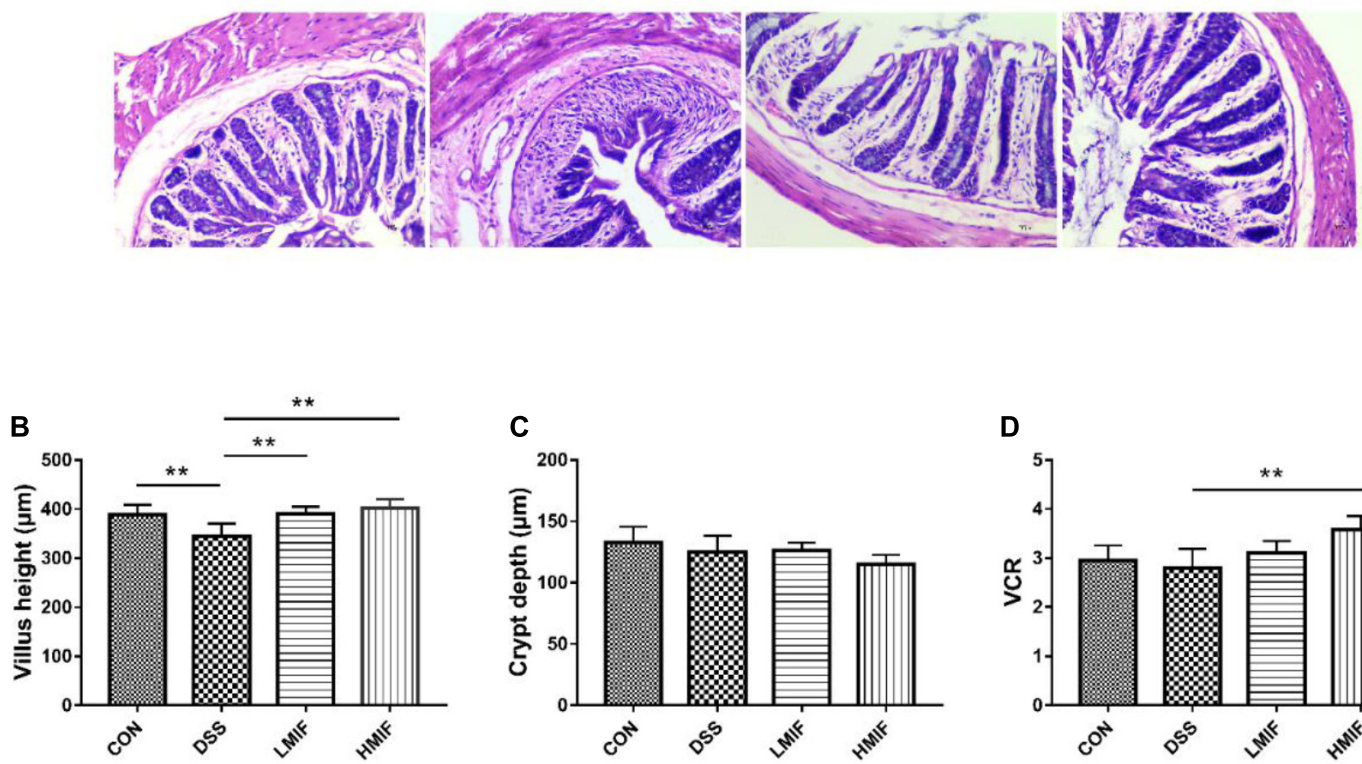

C

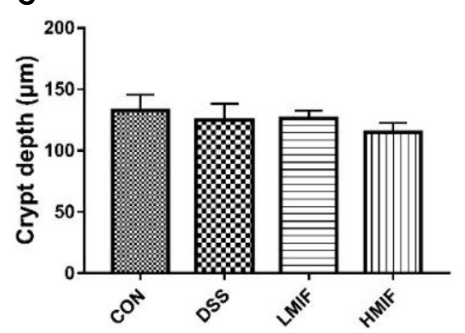

D

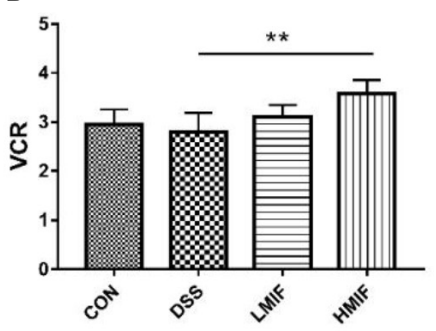

FIGURE 1 | Effects of Morchella importuna flavones on colonic morphologies in dextran sulfate sodium (DSS)-challenged mice. (A) Colonic morphological image; (B) villus height; (C) crypt depth; (D) ratio of villus height to crypt depth (VCR). CON, control; DSS, DSS treatment; LMIF, DSS treatment + $100 \mathrm{mg} / \mathrm{kg}$ fruiting bodies of Morchella importuna (MIF); HMIF, DSS treatment $+200 \mathrm{mg} / \mathrm{kg} \mathrm{MIF.}{ }^{* *} \mathrm{p}<0.01$.

TABLE 3 | Effects of Morchella importuna flavones on the colonic antioxidant capacity in DSS-challenged mice.

\begin{tabular}{lcccc}
\hline Item & \multicolumn{3}{c}{ Treatment $^{\dagger}$} \\
\cline { 2 - 5 } & \multicolumn{1}{c}{ CON } & DSS & DSS + LMIF & $118.46 \pm 5.54^{\star \star}$ \\
SOD, $\mathrm{U} / \mathrm{ml}$ & $145.20 \pm 2.30$ & $93.43 \pm 4.69^{\star \star}$ & $84.70 \pm 3.26^{\star \star}$ & $117.49 \pm 2.37^{\star \star}$ \\
$\mathrm{CAT}, \mathrm{U} / \mathrm{ml}$ & $89.34 \pm 0.88$ & $65.10 \pm 4.16^{\star \star}$ & $5.70 \pm 0.35$ & $88.01 \pm 1.53^{\star \star}$ \\
T-AOC, $\mathrm{U} / \mathrm{ml}$ & $10.49 \pm 0.51$ & $4.80 \pm 0.60^{\star \star}$ & $4.14 \pm 0.27$ & $4.67 \pm 0.61$ \\
MDA, $\mathrm{nmol} / \mathrm{ml}$ & $3.59 \pm 0.24$ & $4.54 \pm 0.32^{\star}$ & $4.08 \pm 0.15$ \\
\hline
\end{tabular}

${ }^{*} p<0.05$ or ${ }^{* *} p<0.01$

${ }^{\dagger}$ CON, control; DSS, dextran sulfate sodium (DSS) treatment; DSS + LMIF, DSS treatment + $100 \mathrm{mg} / \mathrm{kg}$ fruiting bodies of M. importuna (MIF); DSS + HMIF, DSS treatment + $200 \mathrm{mg} / \mathrm{kg}$ MIF. CAT, catalase; MDA, malondialdehyde; SOD, superoxide dismutase; T-AOC, total antioxidant capacity.

TABLE 4 | Effects of Morchella importuna flavones on the colonic cytokine concentrations in DSS-challenged mice.

\begin{tabular}{lrrrr}
\hline Item & \multicolumn{3}{c}{ Treatment $^{\dagger}$} \\
\cline { 2 - 5 } 1. & \multicolumn{1}{c}{ CON } & DSS & DSS + LMIF & DSS + HMIF \\
\hline $\mathrm{LL}-1 \beta, \mathrm{pg} / \mathrm{ml}$ & $8.77 \pm 1.09$ & $15.02 \pm 2.50^{\star *}$ & $12.51 \pm 1.43$ & $10.01 \pm 1.34^{\star *}$ \\
$\mathrm{IL}-6, \mathrm{pg} / \mathrm{ml}$ & $11.30 \pm 1.77$ & $19.53 \pm 4.64^{\star *}$ & $14.95 \pm 3.26$ & $13.45 \pm 2.41^{*}$ \\
$\mathrm{IL}-10, \mathrm{pg} / \mathrm{ml}$ & $55.74 \pm 5.24$ & $38.70 \pm 3.74^{\star *}$ & $50.49 \pm 2.88^{\star *}$ & $53.79 \pm 4.72^{\star *}$ \\
$\mathrm{TNF}-\alpha, \mathrm{pg} / \mathrm{ml}$ & $83.07 \pm 5.20$ & $117.79 \pm 7.30^{\star *}$ & $108.86 \pm 7.36$ & $107.51 \pm 6.86^{\star}$ \\
$\mathrm{IFN}-\gamma, \mathrm{pg} / \mathrm{ml}$ & $49.61 \pm 5.33$ & $77.37 \pm 9.97^{\star *}$ & $68.91 \pm 8.16$ & $65.15 \pm 7.65^{\star}$
\end{tabular}

${ }^{*} p<0.05$ or ${ }^{* *} p<0.01$.

${ }^{\dagger}$ CON, control; DSS, dextran sulfate sodium (DSS) treatment; DSS + LMIF, DSS treatment + $100 \mathrm{mg} / \mathrm{kg}$ fruiting bodies of M. importuna (MIF); DSS + HMIF, DSS treatment + $200 \mathrm{mg} / \mathrm{kg}$ MIF. IFN, interferon; IL, interleukin; TNF, tumor necrosis factor.

Of them, occludin and claudins are considered to be the major integral membrane proteins forming continuous tight junction strands (Furuse et al., 1993; Furuse et al., 1998). Here, we found that MIF supplementation increased the abundances of occludin, claudin-1, and ZO-1 proteins in the colon of DSS-challenged mice, indicating that MIF improved the intestinal barrier integrity. Furthermore, intestinal integrity can be assessed by many markers, such as DAO activity and D-lactate 
A
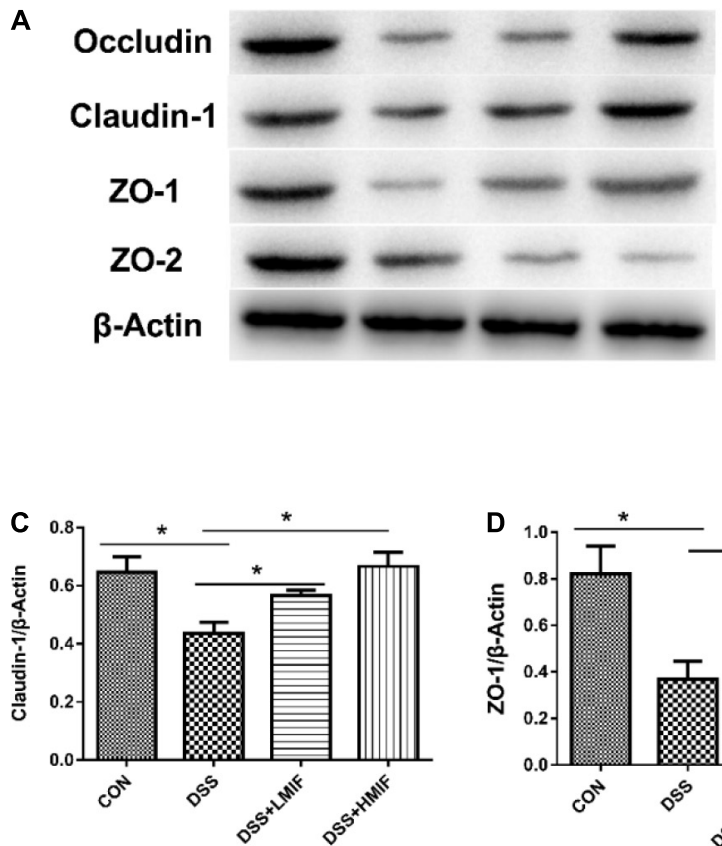
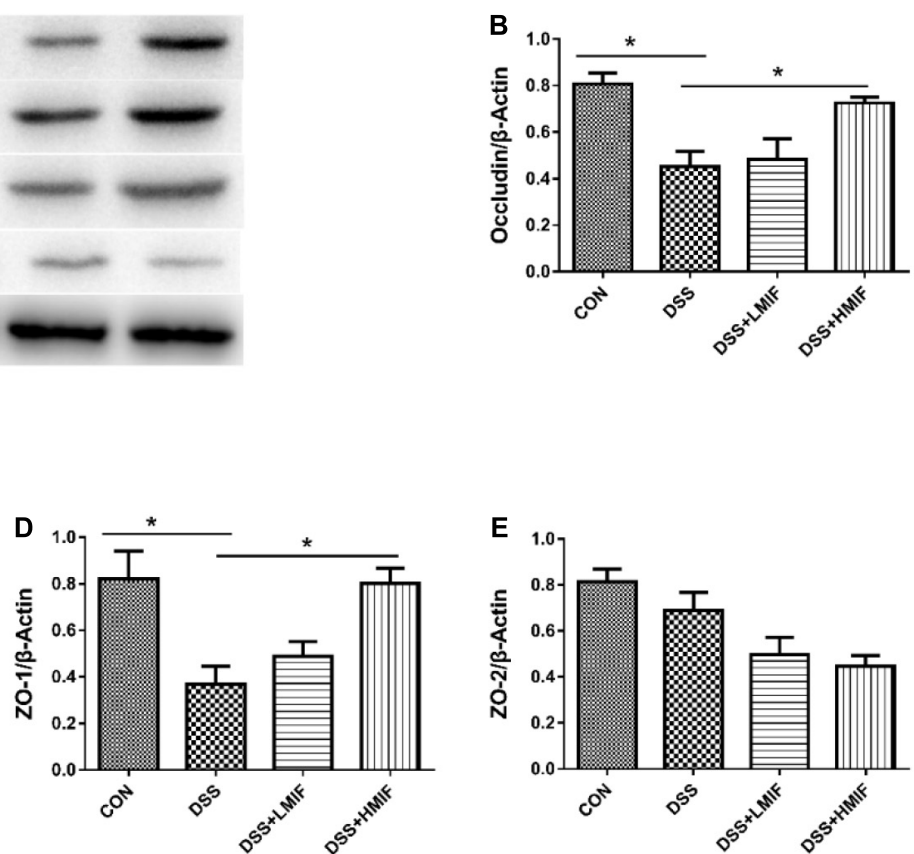

FIGURE 2 | Effects of Morchella importuna flavones on the abundances of the colonic tight junction proteins in dextran sulfate sodium (DSS)-challenged mice. (A) Representative Western blot picture; (B) occludin; (C) claudin-1; (D) zonula occludens-1 (ZO-1); (E) ZO-2. CON, control; DSS, DSS treatment; LMIF, DSS treatment $+100 \mathrm{mg} / \mathrm{kg}$ fruiting bodies of Morchella importuna (MIF); HMIF, DSS treatment $+200 \mathrm{mg} / \mathrm{kg} \mathrm{MIF.}{ }^{*} p<0.05$.

\section{A}
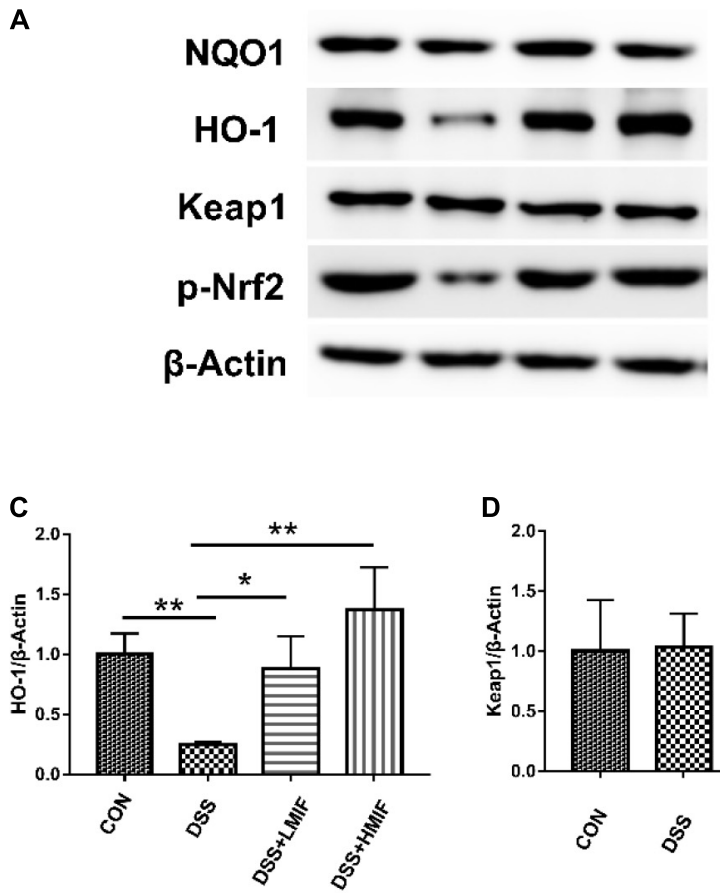

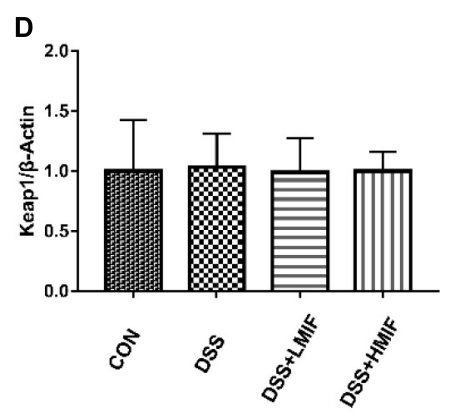

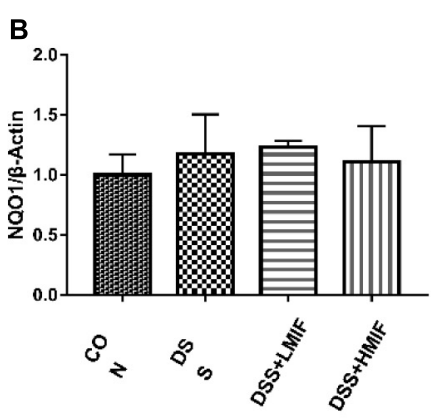

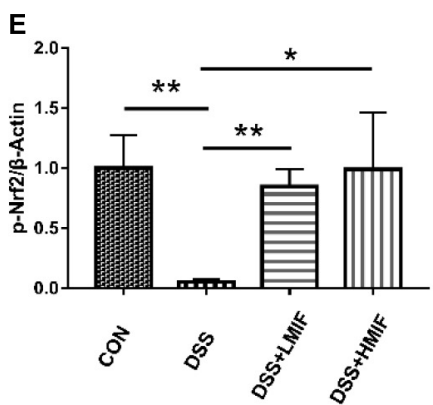

FIGURE 3 | Effects of Morchella importuna flavones on the abundances of the colonic Nrf2 signaling pathway-related proteins in dextran sulfate sodium (DSS)-challenged mice. (A) Representative Western blot picture; (B) NAD(P)H dehydrogenase (quinone 1) (NQO-1); (C) heme oxygenase-1 (HO-1); (D) Keap1; (E) p-Nrf2. CON, control; DSS, DSS treatment; LMIF, DSS treatment + 100 mg/kg fruiting bodies of Morchella importuna (MIF); HMIF, DSS treatment + $200 \mathrm{mg} / \mathrm{kg}$ MIF. ${ }^{*} p<0.05$ or ${ }^{* *} p<0.01$. 


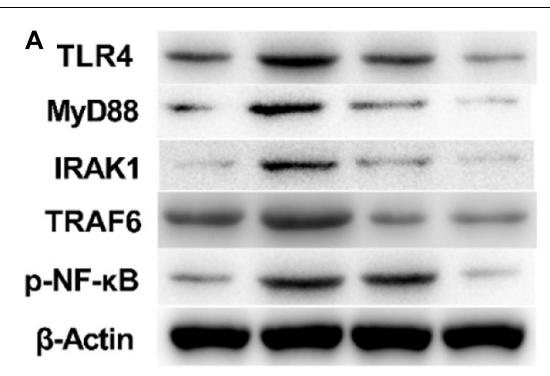

D

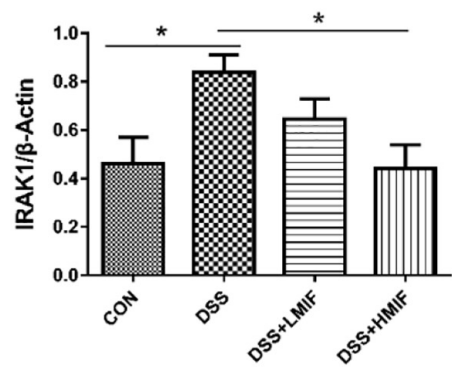

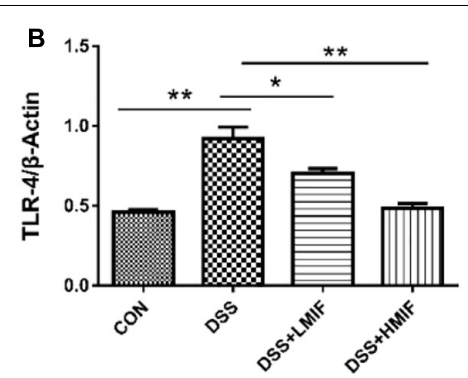
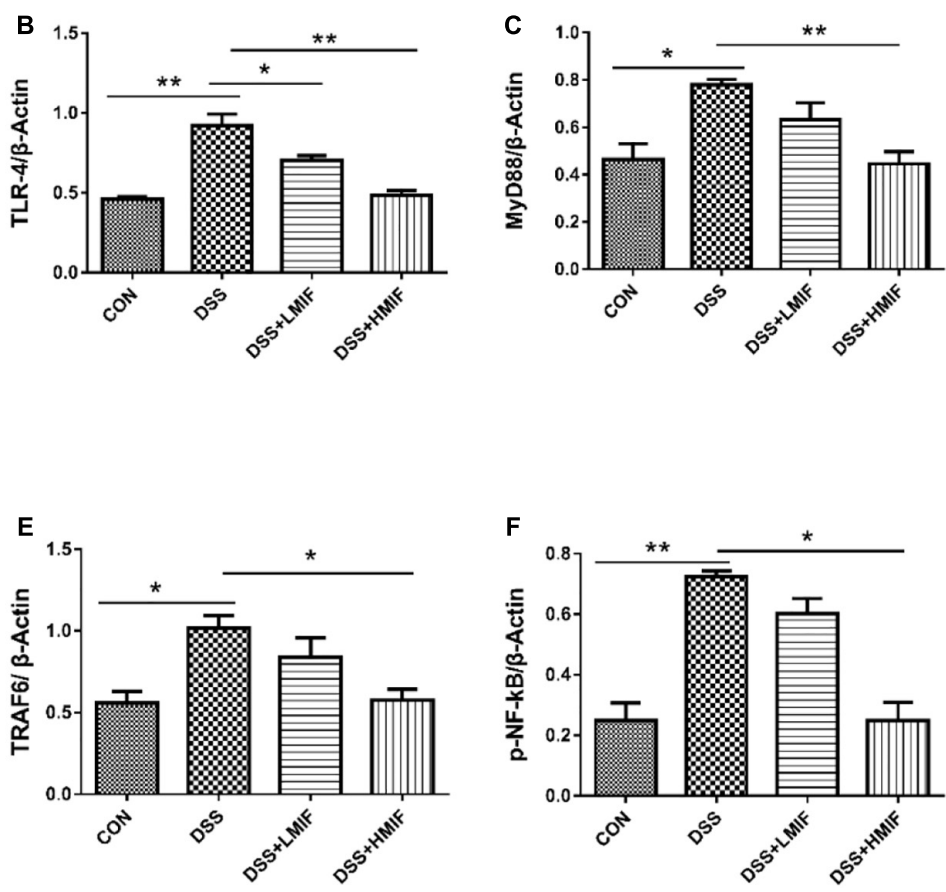

FIGURE 4 | Effects of Morchella importuna flavones on the abundances of the colonic Toll-like receptor 4 (TLR4) signaling pathway-related proteins in dextran sulfate sodium (DSS)-challenged mice. (A) Representative Western blot picture; (B) TLR4; (C) MyD88; (D) IL-1 receptor-associated kinase 1 (IRAK1); (E) TNF receptor-associated factor 6 (TRAF6); (F) p-NF-kB p65. CON, control; DSS, DSS treatment; LMIF, DSS treatment + 100 mg/kg fruiting bodies of Morchella importuna (MIF); HMIF, DSS treatment $+200 \mathrm{mg} / \mathrm{kg} \mathrm{MIF.}{ }^{*} p<0.05$ or ${ }^{* *} p<0.01$.

TABLE 5 | Effects of ethanol extracts from Morchella importuna on the $\alpha$-diversity indexes in the colon of DSS-challenged mice.

\begin{tabular}{lccr}
\hline Item & \multicolumn{3}{c}{ Treatment $^{\dagger}$} \\
\cline { 2 - 4 } & CON & DSS & \multicolumn{1}{c}{ DSS + HMIF } \\
\cline { 2 - 4 } Chao1 index & $393.09 \pm 30.64$ & $371.89 \pm 24.59$ & $364.72 \pm 12.33$ \\
ACE index & $390.55 \pm 23.95$ & $374.08 \pm 24.29$ & $369.79 \pm 13.76$ \\
Shannon index & $6.27 \pm 0.07$ & $5.71 \pm 0.20^{\star \star}$ & $6.04 \pm 0.04^{\star \star}$ \\
Simpson index & $0.97 \pm 0.00$ & $0.94 \pm 0.01^{\star \star}$ & $0.96 \pm 0.00^{\star \star}$
\end{tabular}

${ }^{* *} p<0.01$.

${ }^{\dagger}$ CON, control; DSS, dextran sulfate sodium (DSS) treatment; DSS + HMIF, DSS treatment $+200 \mathrm{mg} / \mathrm{kg}$ fruiting bodies of M. importuna (MIF).

concentration (Nielsen et al., 2011; Liu et al., 2012). Consistent with improved intestinal barrier function, MIF improved colonic barrier integrity in DSS-challenged mice, as evinced by decreased serum DAO activity and D-lactate concentration.

Intestinal antioxidant activity is closely related to intestinal health, which in turn is considered to be associated with intestinal structure (Jia et al., 2019). SOD and CAT are important antioxidant enzymes that can scavenge free radicals to defend against oxidative injury (Slavić et al., 2006; Lestaevel et al., 2009). We found lower SOD and CAT activities in DSS-challenged mice than in control mice, indicating that DSS challenge causes severe oxidative damage to the colon in mice. However, MIF attenuated the DSS-induced reduction of SOD and CAT activities in the colon, implying that MIF exerts a protective effect against intestinal oxidative damage caused by DSS challenge. The elevated antioxidant capacity was also supported by the expression of several critical antioxidant genes. Nrf2, one of the key transcription factors, plays a vital role in maintaining the activities of antioxidant enzymes (Cheng et al., 2015). The HO- 1 is located downstream of the Nrf2 and acts as one of the key antioxidant enzymes (Han et al., 2017). In this study, MIF significantly elevated the protein levels of p-Nrf2 and HO1 in the DSS-challenged mice, further indicating the antioxidant capacity of MIF in DSS-challenged mice. These results could determine that dietary MIF supplementation maintained the intestinal barrier function of mice under DSS challenge, to some extent, by enhancing intestinal antioxidant ability.

The unsettled balance between anti- and pro-inflammatory cytokines has been found to induce intestinal inflammatory injury in the DSS-challenged mice (Choi et al., 2017; Yin et al., 2020). In this study, MIF treatment inhibited inflammatory responses as evinced by decreasing proinflammatory cytokine (IL-1 $\beta$, TNF- $\alpha$, and IFN- $\gamma$ ) concentrations in the colon following DSS treatment. Contrary to the aforementioned cytokines, IL-10, as an anti-inflammatory cytokine, has been demonstrated to protect colonic inflammatory injury (Hasnain et al., 2013). Interestingly, MIF treatment also elevated the IL-10 concentration in the colon after DSS challenge. These results suggest that the beneficial effects of MIF against DSS-induced intestinal inflammatory injury were related to the regulation of the production of pro-inflammatory and anti-inflammatory cytokines. To elucidate the molecular 


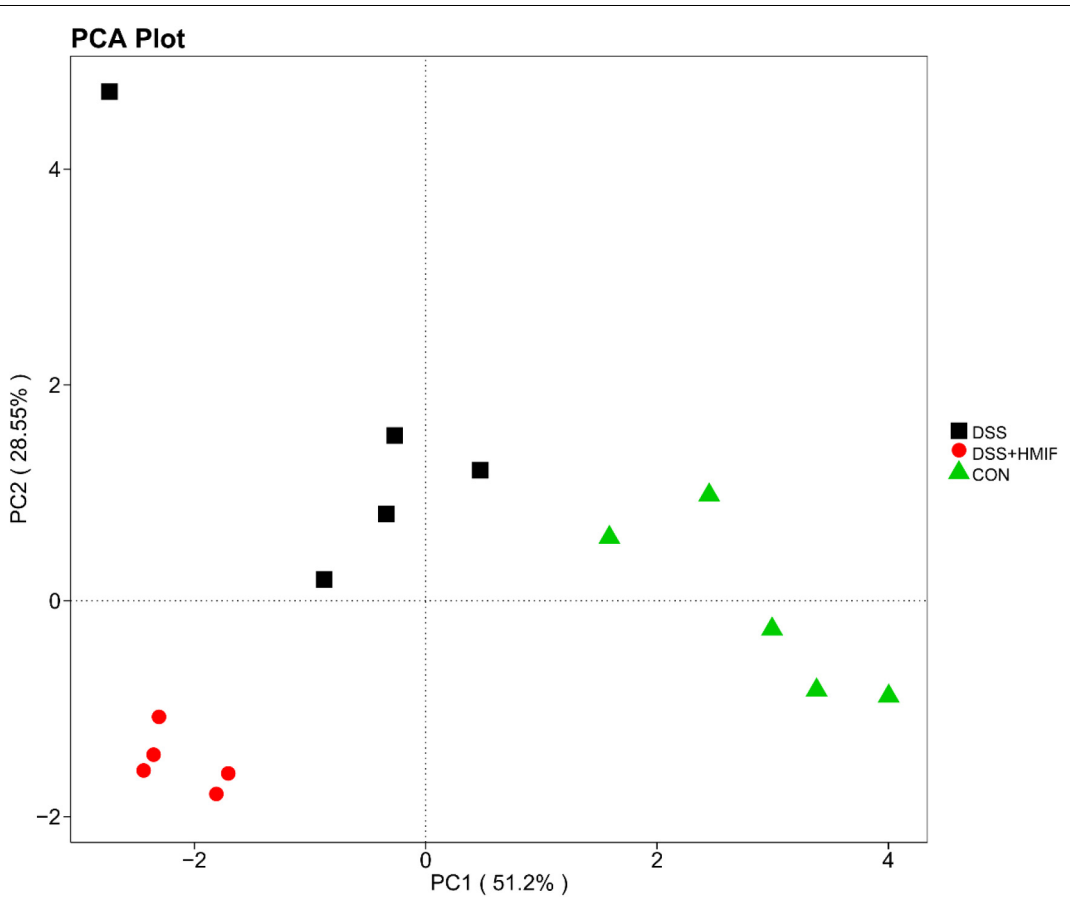

FIGURE 5 | Comparison of the colonic microbiota composition among the three groups. A principal coordinate analysis (PCoA) was used to visualize the weighted UniFrac distances of the fecal samples from the C57BL/6J mice. CON, control; DSS, dextran sulfate sodium (DSS) treatment; HMIF, DSS treatment + $200 \mathrm{mg} / \mathrm{kg}$ fruiting bodies of Morchella importuna (MIF).

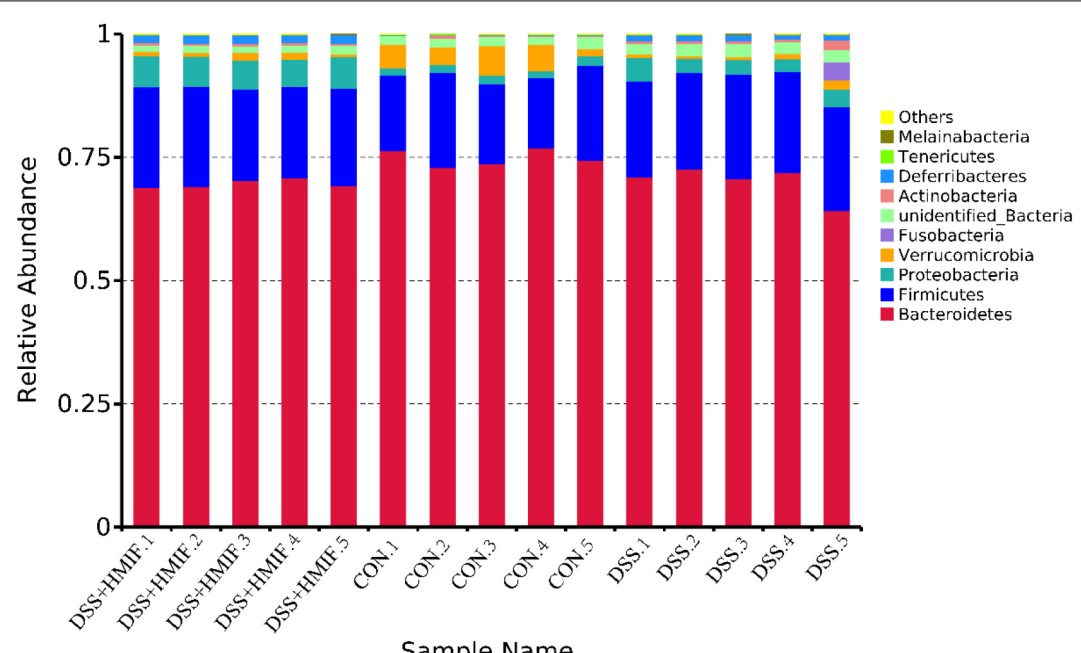

FIGURE 6 | Relative abundances of the dominant bacteria at phylum level in the colon of C57BL/6J mice among the three groups. CON, control; DSS, dextran sulfate sodium (DSS) treatment; HMIF, DSS treatment +200 mg/kg fruiting bodies of Morchella importuna (MIF).

mechanisms by which MIF attenuates intestinal inflammatory responses, we investigated the TLR4 signaling pathway-related protein expression.

Activation of TLR4 signaling pathway plays an important role in defensive responses against invading pathogens via triggering the secretion of pro-inflammatory cytokines (Wang et al., 2017). However, the aberrant activation of TLR4 signaling pathway elicits collateral host intestinal injury (Coll and O'Neill,
2010). In the present study, we observed that colonic protein abundances of TLR4 and its downstream signals, such as MyD88, IRAK1, and TRAF6, were reduced in MIF-treated DSSchallenged mice. NF-кB is a critical nuclear transcription factor downstream of the TLR4 signaling pathway that regulates the production of pro-inflammatory cytokines (Sabroe et al., 2008). The inactivation of NF- $\mathrm{B}$ has been proven to be able to alleviate the severity of intestinal inflammatory injury (Kang et al., 2017; 
Wan et al., 2019). Here, the colonic protein abundance of p-NF$\kappa \mathrm{B}$ p65 in DSS-challenged mice was also decreased by MIF supplementation. These results suggest that MIF attenuates DSS-induced intestinal inflammatory injury via decreasing proinflammatory cytokine release through inhibiting the TLR4/NF$\kappa \mathrm{B}$ signaling pathway.

Although the exact pathogenesis of inflammatory bowel disease is complex, intestinal microbiota disorder is one of the most important observations (Zhai et al., 2019). As noted previously, the species, richness, and abundance of intestinal microbiota were markedly decreased in patients with inflammatory bowel disease (Zmora et al., 2019). In this study, we found that colonic microbiota in DSS-treated mice following MIF supplementation exhibit more diversity of evenness and richness than those in DSS-treated mice, as they have higher Shannon and Simpson indices. Low microbial diversity is often regarded as being associated with some infective intestinal disease, such as inflammatory bowel disease (Manichanh et al., 2006). Thus, the increase in microbial diversity induced by MIF may play a positive role in the colonic health of mice, which partly elucidates the alleviation of intestinal inflammatory injury in these mice. Furthermore, we found that MIF increased the abundances of Proteobacteria, Deferribacteres, and Melainabacteria, suggesting that these bacteria may play an essential role in MIF treatment of inflammatory bowel disease.

\section{CONCLUSION}

To summarize, our findings indicate that MIF have beneficial effects on modulating intestinal barrier function and microbiota in DSS-challenged mice. The reduced inflammatory factor production and enhanced antioxidant capacity caused by MIF may be associated with inhibited NF-кB signaling pathway and activated Nrf2 signaling pathway, respectively. These results offer a molecular basis for the potential contribution of MIF to the prevention of intestinal barrier injury.

\section{REFERENCES}

Anderson, J. M., Balda, M. S., and Fanning, A. S. (1993). The structure and regulation of tight junctions. Curr. Opin. Cell Biol. 5, 772-778.

Bassaganya-Riera, J., and Hontecillas, R. (2006). CLA and n-3 PUFA differentially modulate clinical activity and colonic PPAR-responsive gene expression in a pig model of experimental IBD. Clin. Nut. 25, 454-465. doi: 10.1016/j.clnu.2005. 12.008

Cheng, L., Jin, Z., Zhao, R., Ren, K., Deng, C., and Yu, S. (2015). Resveratrol attenuates inflammation and oxidative stress induced by myocardial ischemiareperfusion injury: role of Nrf2/ARE pathway. Int. J. Clin. Exp. Med. 8:10420.

Choi, J. H., Chung, K. S., Jin, B. R., Cheon, S. Y., Nugroho, A., Roh, S. S., et al. (2017). Anti-inflammatory effects of an ethanol extract of Aster glehni via inhibition of NF- $\mathrm{B}$ activation in mice with DSS-induced colitis. Food Function 8, 2611-2620. doi: 10.1039/c7fo00369b

Coll, R. C., and O'Neill, L. A. (2010). New insights into the regulation of signalling by toll-like receptors and nod-like receptors. J. Innate Immunity 2, 406-421. doi: 10.1159/000315469

Edgar, R. C. (2013). UPARSE: highly accurate OTU sequences from microbial amplicon reads. Nat. Methods 10, 996-998. doi: 10.1038/nmeth.2604

\section{DATA AVAILABILITY STATEMENT}

The datasets presented in this study can be found in online repositories. The names of the repository/repositories and accession number(s) can be found in the article/ Supplementary Material.

\section{ETHICS STATEMENT}

The animal study was reviewed and approved by the Animal Care and Use Committee of Sichuan Academy of Agricultural Sciences (Chengdu, China).

\section{AUTHOR CONTRIBUTIONS}

BG and WP conceived this study. YX wrote the manuscript. LX, JT, XH, ZZ, YC, and JZ carried out the experiments and performed data analyses. All authors contributed to the article and approved the submitted version.

\section{FUNDING}

This study was financially supported by the special fund of Chengdu Local Finance (NASC2020AR06) and the Key Research and Development Project of Sichuan Science and Technology Plan (2021YFN0094).

\section{SUPPLEMENTARY MATERIAL}

The Supplementary Material for this article can be found online at: https://www.frontiersin.org/articles/10.3389/fmicb. 2021.742033/full\#supplementary-material

Edgar, R. C., Haas, B. J., Clemente, J. C., Quince, C., and Knight, R. (2011). UCHIME improves sensitivity and speed of chimera detection. Bioinformatics 27, 2194-2200. doi: 10.1093/bioinformatics/btr381

Fang, T., Wu, X., Cao, W., Jia, G., Zhao, H., Chen, X., et al. (2017). Effects of dietary fiber on the antioxidant capacity, immune status, and antioxidant-relative signaling molecular gene expression in rat organs. RSC Adv. 7, 19611-19620. doi: $10.1039 / \mathrm{c} 7 \mathrm{ra02464a}$

Furuse, M., Fujita, K., Hiiragi, T., Fujimoto, K., and Tsukita, S. (1998). Claudin-1 and-2: novel integral membrane proteins localizing at tight junctions with no sequence similarity to occludin. J. Cell Biol. 141, 1539-1550. doi: 10.1083/jcb. 141.7.1539

Furuse, M., Hirase, T., Itoh, M., Nagafuchi, A., Yonemura, S., Tsukita, S., et al. (1993). Occludin: a novel integral membrane protein localizing at tight junctions. J. Cell Biol. 123, 1777-1788. doi: 10.1083/jcb.123.6.1777

Haas, B. J., Gevers, D., Earl, A. M., Feldgarden, M., Ward, D. V., Giannoukos, G., et al. (2011). Chimeric 16S rRNA sequence formation and detection in Sanger and 454-pyrosequenced PCR amplicons. Genome Res. 21, 494-504. doi: $10.1101 /$ gr.112730.110

Halpern, M. D., and Denning, P. W. (2015). The role of intestinal epithelial barrier function in the development of NEC. Tissue Barriers 3:e1000707. doi: 10.1080/ 21688370.2014.1000707 
Han, D., Chen, W., Gu, X., Shan, R., Zou, J., Liu, G., et al. (2017). Cytoprotective effect of chlorogenic acid against hydrogen peroxide-induced oxidative stress in MC3T3-E1 cells through PI3K/Akt-mediated Nrf2/HO-1 signaling pathway. Oncotarget 8:14680. doi: 10.18632/oncotarget.14747

Hasnain, S. Z., Tauro, S., Das, I., Tong, H., Chen, A. C. H., Jeffery, P. L., et al. (2013). IL-10 promotes production of intestinal mucus by suppressing protein misfolding and endoplasmic reticulum stress in goblet cells. Gastroenterology 144, 357-368.e359.

Heleno, S. A., Stojković, D., Barros, L., Glamočlija, J., Soković, M., Martins, A., et al. (2013). A comparative study of chemical composition, antioxidant and antimicrobial properties of Morchella esculenta (L.) Pers. from Portugal and Serbia. Food Res. Int. 51, 236-243. doi: 10.1016/j.foodres.2012. 12.020

Huang, M., Zhang, S., Zhang, M., Ou, S., and Pan, Z. (2012). Effects of polysaccharides from morchella conica on nitric oxide production in lipopolysaccharide-treated macrophages. Appl. Microbiol. Biotechnol. 94, 763771. doi: 10.1007/s00253-011-3711-7

Jia, Z., Wu, A., He, M., Zhang, L., Wang, C., and Chen, A. (2019) Metabolites of stable fly reduce diarrhea in mice by modulating the immune system, antioxidants, and composition of gut microbiota. Microbial. Pathog. 134:103557. doi: 10.1016/j.micpath.2019.103557

Kang, J. H., Choi, S., Jang, J. E., Ramalingam, P., Ko, Y. T., Kim, S. Y., et al. (2017). Wasabia japonica is a potential functional food to prevent colitis via inhibiting the NF-кB signaling pathway. Food Function 8, 2865-2874. doi: $10.1039 / \mathrm{c} 7$ fo00576h

Kim, J. A., Lau, E., Tay, D., and De Blanco, E. J. C. (2011). Antioxidant and NF-кB inhibitory constituents isolated from Morchella esculenta. Nat. Product Res. 25, 1412-1417. doi: 10.1080/14786410802425746

Lestaevel, P., Romero, E., Dhieux, B., Soussan, H. B., Berradi, H., Dublineau, I., et al. (2009). Different pattern of brain pro-/anti-oxidant activity between depleted and enriched uranium in chronically exposed rats. Toxicology 258, 1-9. doi: $10.1016 /$ j.tox.2008.12.021

Liu, Y., Chen, F., Odle, J., Lin, X., Jacobi, S. K., Zhu, H., et al. (2012). Fish oil enhances intestinal integrity and inhibits TLR4 and NOD2 signaling pathways in weaned pigs after LPS challenge. J. Nut. 142, 2017-2024.

Liu, Y., Huang, J., Hou, Y., Zhu, H., Zhao, S., Ding, B., et al. (2008). Dietary arginine supplementation alleviates intestinal mucosal disruption induced by Escherichia coli lipopolysaccharide in weaned pigs. Br. J. Nut. 100, 552-560. doi: 10.1017/s0007114508911612

Manichanh, C., Rigottier-Gois, L., Bonnaud, E., Gloux, K., Pelletier, E., Frangeul, L., et al. (2006). Reduced diversity of faecal microbiota in Crohn's disease revealed by a metagenomic approach. Gut 55, 205-211. doi: 10.1136/gut.2005.073817

Martin, M. (2011). Cutadapt removes adapter sequences from high-throughput sequencing reads. EMBnet. J. 17, 10-12. doi: 10.14806/ej.17.1.200

Mau, J. L., Chang, C. N., Huang, S. J., and Chen, C. C. (2004). Antioxidant properties of methanolic extracts from Grifola frondosa, Morchella esculenta and Termitomyces albuminosus mycelia. Food Chem. 87, 111-118. doi: 10.1016/ j.foodchem.2003.10.026

Nielsen, C., Lindholt, J. S., Erlandsen, E. J., and Mortensen, F. V. (2011). D-lactate as a marker of venous-induced intestinal ischemia: an experimental study in pigs. Int. J. Surg. 9, 428-432. doi: 10.1016/j.ijsu.2011.04.004

Peterson, L. W., and Artis, D. (2014). Intestinal epithelial cells: regulators of barrier function and immune homeostasis. Nat. Rev. Immunol. 14, 141-153. doi: $10.1038 /$ nri3608

Qin, Q., Xu, X., Wang, X., Wu, H., Zhu, H., Hou, Y., et al. (2018). Glutamate alleviates intestinal injury, maintains mTOR and suppresses TLR4 and NOD signaling pathways in weanling pigs challenged with lipopolysaccharide. Sci. Rep. 8, 1-10.

Sabroe, I., Parker, L., Dower, S., and Whyte, M. K. B. (2008). The role of TLR activation in inflammation. J. Pathol. 214, 126-135. doi: 10.1002/path.2264

Slavić, M., Slavić, M., Slavić, M., Appiah, I., Appiah, I., Appiah, I., et al. (2006). The anti-oxidative defence system in the isolated rat uterus during spontaneous rhythmic activity. Acta Physiol. Hung. 93, 335-339. doi: 10.1556/aphysiol.93. 2006.4.9
Tian, S., Wang, J., Yu, H., Wang, J., and Zhu, W. Y. (2019). Changes in ileal microbial composition and microbial metabolism by an early-life galactooligosaccharides intervention in a neonatal porcine model. Nutrients 11:1753. doi: $10.3390 /$ nu11081753

Tietel, Z., and Masaphy, S. (2018). True morels (Morchella)Nutritional and phytochemical composition, health benefits and flavor: a review. Crit. Rev. Food Sci. Nut. 58, 1888-1901. doi: 10.1080/10408398.2017.1285269

Ulluwishewa, D., Anderson, R. C., Mcnabb, W. C., Moughan, P. J., Wells, J. M., and Roy, N. C. (2011). Regulation of tight junction permeability by intestinal bacteria and dietary components. J. Nut. 141, 769-776. doi: 10.3945/jn.110. 135657

Wan, J., Zhang, J., Chen, D., Yu, B., Huang, Z., Mao, X., et al. (2020). Alterations in intestinal microbiota by alginate oligosaccharide improve intestinal barrier integrity in weaned pigs. J. Funct. Foods 71:104040. doi: 10.1016/j.jff.2020. 104040

Wan, J., Zhang, J., Wu, G., Chen, D., Yu, B., Huang, Z., et al. (2019). Amelioration of enterotoxigenic Escherichia coli-induced intestinal barrier disruption by low-molecular-weight chitosan in weaned pigs is related to suppressed intestinal inflammation and apoptosis. Int. J. Mol. Sci. 20:3485 doi: 10.3390/ijms20143485

Wang, B., Wu, G., Zhou, Z., Dai, Z., Sun, Y., Ji, Y., et al. (2015). Glutamine and intestinal barrier function. Amino Acids 47, 2143-2154.

Wang, H., Liu, Y., Shi, H., Wang, X., Zhu, H., Pi, D., et al. (2017). Aspartate attenuates intestinal injury and inhibits TLR4 and NODs/NF- $\mathrm{B}$ and $\mathrm{p} 38$ signaling in weaned pigs after LPS challenge. Eur. J. Nut. 56, 1433-1443. doi: 10.1007/s00394-016-1189-X

Wang, J., Xiao, J., Geng, F., Li, X., Yu, J., Zhang, Y., et al. (2019). Metabolic and proteomic analysis of morel fruiting body (Morchella importuna). J. Food Composit. Anal. 76, 51-57. doi: 10.1016/j.jfca.2018.12.006

Xiong, C., Luo, Q., Huang, W. L., Li, Q., Chen, C., Chen, Z. Q., et al. (2017). The potential neuritogenic activity of aqueous extracts from Morchella importuna in rat pheochromocytoma cells. Food Sci. Biotechnol. 26, 1685-1692. doi: 10.1007/ s10068-017-0224-x

Yang, C., Ferket, P. R., Hong, Q., Zhou, J., Cao, G., Zhou, L., et al. (2012). Effect of chito-oligosaccharide on growth performance, intestinal barrier function, intestinal morphology and cecal microflora in weaned pigs. J. Animal Sci. 90, 2671-2676. doi: 10.2527/jas.2011-4699

Yin, S., Yang, H., Tao, Y., Wei, S., Li, L., Liu, M., et al. (2020). Artesunate ameliorates DSS-induced ulcerative colitis by protecting intestinal barrier and inhibiting inflammatory response. Inflammation 43, 1-12.

Zhai, Z., Zhang, F., Cao, R., Ni, X., Xin, Z., Deng, J., et al. (2019). Cecropin a alleviates inflammation through modulating the gut microbiota of C57BL/6 mice with DSS-induced IBD. Front. Microbiol. 10:1595.

Zmora, N., Suez, J., and Elinav, E. (2019). You are what you eat: diet, health and the gut microbiota. Nat. Rev. Gastroenterol. Hepatol. 16, 35-56. doi: 10.1038/ s41575-018-0061-2

Conflict of Interest: The authors declare that the research was conducted in the absence of any commercial or financial relationships that could be construed as a potential conflict of interest.

Publisher's Note: All claims expressed in this article are solely those of the authors and do not necessarily represent those of their affiliated organizations, or those of the publisher, the editors and the reviewers. Any product that may be evaluated in this article, or claim that may be made by its manufacturer, is not guaranteed or endorsed by the publisher.

Copyright (c) 2021 Xu, Xie, Tang, He, Zhang, Chen, Zhou, Gan and Peng. This is an open-access article distributed under the terms of the Creative Commons Attribution License (CC BY). The use, distribution or reproduction in other forums is permitted, provided the original author(s) and the copyright owner(s) are credited and that the original publication in this journal is cited, in accordance with accepted academic practice. No use, distribution or reproduction is permitted which does not comply with these terms. 